\title{
Open access: challenges and barriers to African scholars'
}

\author{
Johannes Britz ${ }^{2}$ \\ University of Wisconsin-Milwaukee \\ University of Pretoria \\ britz@uwm.edu
}

\section{Introduction}

The price of journals (referring here to e-journals as well as hard copies) has risen dramatically over the past three decades, to the point that they can hardly be afforded by academic libraries in rich countries such as the USA. This evidently has even worse implications for academic libraries in Africa, and most of Africa's scholarly community therefore remains marginalized in terms of access to the global body of knowledge.

The introduction of the Internet, accompanied by the ability to digitize and manipulate information, has not only changed the knowledge and information landscape permanently, but also changed the publishing industry. It has, for the first time, become possible to reproduce and distribute information products and services at nearly zero marginal cost (Anderson, 2006). The only requirement is access to a computer, the Internet and relevant websites. This new model has led to the global Open Access (OA) movement, whose main aim is to distribute scholarly journals free of charge to its end users. For the first time, there is therefore a real opportunity for African scholars to gain, free of charge (or at least at a very affordable cost), access to digital scholarly journals and the scholarly works of others. The OA movement has, however, not led to the free flow of information on the African continent. While expectations have been raised, there are still many stumbling blocks prohibiting African scholars from fully participating in and benefiting from the OA movement.

This paper will highlight some of these stumbling blocks, discussed within the moral framework of the right of access to information. The paper is structured in the following manner: First, the notion of OA will be discussed. Following this, I will elaborate on the right of access to information, thereby establishing the moral framework. The third and final part will address some of the challenges and obstacles facing African scholars regarding access to scholarly work via OA.

\section{Understanding the moral context: the right of access to information and the right to communicate}

The OA movement is in essence about providing scholars access to the works of others free of charge (as end-users). It operates on the basic principles of the economics of information, allowing the reproduction and distribution of information products and services at nearly zero marginal cost (Evans and Wurster, 1997). It is, however, driven by a moral imperative that scholars have the right to the works of others, or in other words, the right of access to information, the right to communicate and the right to know. There is further a strong sense that these should be enabling (or affordable) rights. In the following paragraphs I will elaborate on these information-related rights.

Above all, communication is an essential human process that makes both individual expression and societal structure possible. Habermas (1989) and Fisher (1982) view access to information as a fundamental and necessary precondition for personal development and socio-economic participation. Benkler (2006) further argues that access to information and the ability to communicate are central to human freedom and human development. The new economics of information, introduced by modern Information and Communication Technologies (ICTs), have furthermore made it possible to communicate beyond face-to-face interaction and reach the entire globe by means of modern inventions such as electronic journals and e-mail. This is also the reason why Hamelink (2003) argues that we should move beyond information and knowledge societies towards communication societies. He argues that the current set of human rights as defined by the UN needs to be updated to reflect these developments.

The argument that access to information is an instrumental and individual as well as social right not only implies the protection of this right, for example in a constitution and by means of legislation, but also the enabling of this right. Based on Sen's capability approach (1993) one can further argue that society has a moral obligation and social responsibility towards creating an accessible information infrastructure together with a legal regime that would allow citizens not only the protection of this right, but also the means and ways by which they can exercise it. This is particularly true of Africa where there is a lack of such a policy framework. Article 28 of the United Nations Declaration of Human Rights states: "Everyone is entitled to a social and international order in which the rights and freedoms set forth in this Declaration can be fully realized" (United Nations, 1997).

I. This research is partly based on published doctoral research done by the author.

2. Johannes Britz, PhD, is Professor and Dean School of Information Studies, University of Wisconsin, Milwaukee, USA. He was the Key Note speaker at the Conference 
Based on these moral premises, it can therefore be argued that the distribution of scholarly journals in digital format should not be restricted by the current intellectual property regimes or by an economic model that does not support affordable access thereto.

\section{What is Open Access?}

Before I elaborate on the obstacles that African scholars face with regard to OA, it is important to understand what is meant by open access. From an economic as well as legal perspective, OA does not mean the free flow of free information, nor does it promote 'illegal' intellectual property-related activities. The Budapest Open Access Initiative defines OA as follows: "There are many degrees and kinds of wider and easier access to this literature. By 'open access' to this literature, we mean its free availability on the public Internet, permitting any users to read, download, copy, distribute, print, search, or link to the full texts of these articles, crawl them for indexing, pass them as data to software, or use them for any other lawful purpose, without financial, legal, or technical barriers other than those inseparable from gaining access to the Internet itself. The only constraint on reproduction and distribution, and the only role for copyright in this domain, should be to give authors control over the integrity of their work and the right to be properly acknowledged and cited" (http://www.soros.org/openaccess/read.shtml).

Peter Suber (2007) provides an excellent overview of open access that is published on the website (http:// www.earlham.edu/ peters/fos/overview.htm). I summarize the most important aspects of OA based on his description.

- OA literature is mostly confined to scholarly publications and can be in any digital format, including text, movies and images;

- It is free of charge and also free of most intellectual property-related restrictions, including copyright and licensing. It does, however, protect the moral rights of authors as well as conditions for use - normally under the Creative Commons License;

- OA is therefore compatible with intellectual property regimes;

- It is not a new business model aiming to make money - it simply removes the pricing barrier faced by the end user of information;

- It recognizes the fact that there are still production costs involved;

- It is "royalty free literature". This is a concept coined by Peter Suber to capture the notion that authors make their works available without the expectation of payment or any other form of compensation;

- As with scholarly journals, OA is peer-reviewed;

- The main focus of $O A$ is to make available, for free, tax-payer funded research;

- The two primary vehicles for the distribution of research articles are $O A$ journals and $O A$ archives and/or repositories;

- OA is not the same as universal access. There are still many restrictions in the OA environment, some of which include language barriers, censorship, lack of access to the Internet and handicap-related access barriers (Suber refers here to the fact that many websites still do not accommodate handicapped people); and

- OA serves the interest of many people and groups, including but not limited to users, authors, governments, funding agencies and libraries.

\section{Challenges facing OA in Africa}

In many ways, OA can provide the necessary solutions to the educational challenges faced on the African continent - in particular the much needed access to high quality academic journals. For example, African academic libraries can subscribe to free $O A$ journals, and scholars and researchers can access free content (be it in OA journals or OA repositories) on the Web.

There are, however, significant problems facing African academics regarding access to OA scholarly information. I mention a few.

\section{Information infrastructure challenges}

The first, and probably most important, is the lack of well developed information infrastructure on the continent. There is general agreement amongst economists and politicians that the backbone of any advanced country operating in the global knowledge society is well-developed and maintained information infrastructure, i.e. infrastructure that not only enables the communication and sharing of information, but also the ability to participate in global, digital, economic and sociopolitical activities. Such information-based infrastructure must allow “...the spread of national, international and genuinely global information exchanges between banks, corporations, governments, universities and voluntary bodies...” (Webster, 2002:10).

A well developed and maintained information infrastructure covers of course a variety of issues that ranges from the traditional provision of libraries, publishers and booksellers, to the distribution of open access literature via the Internet.

Inkanyiso, Jnl Hum \& Soc Sci 2009, I(I) 
Naisbitt (1984:28) correctly points out that "...the computer technology is to the information age what mechanization was to the industrial revolution".

The problem is, of course, that many countries in Africa lack such sophisticated information infrastructure. This has led to dire consequences for many of these countries as they are prevented from effectively participating in the global information-based economy and are in many instances excluded from unhindered access to OA literature. Kularatne (1997: I I8), critique on the developing world namely: "Whether a coordinated and organised national information policy exists in a country or not, there are certain fundamental inadequacies in the information infrastructure of many Third World countries" is still applicable in many cases today. Castells (1998) predicted a particularly bleak future for countries in sub-Saharan Africa. He referred to Africa's technological apartheid at the dawn of the information age caused by a lack of infrastructure or human capacity to deploy and utilize technology. It is worthwhile quoting Castells (1998:95) at length:

"Because of the inability of African countries to produce/use advanced technological equipment and knowhow, their imbalance of trade becomes unsustainable, as the added value of technology - intensive goods and services - continues to increase vis-à-vis the value of raw materials and agricultural products, limiting their capacity to import inputs necessary to keep their commodity production systems in operation. It follows a downward spiral of competitiveness, as Africa becomes increasingly marginalized in the informational/global economy by the leap of technological change. The disinformation of Africa at the dawn of the Information Age may be the most lasting wound inflicted on this continent by new patterns of dependency, aggravated by the policies of the predatory state".

Much of what Castells wrote and predicted in 1998 was still a reality in Africa in 2004. This was confirmed by a survey that was done in 2004 by the New Economic Partnership for Economic Development (NEPAD) in Africa. One of the main priorities of NEPAD (2004) is "... the building and improving infrastructure including ICT". As a direct outcome of this priority NEPAD launched a survey on the current status of ICT use and policies in Africa. An alarming, but not surprising finding of the study was that enabling laws to drive e-strategies in Africa are nearly non-existent. Mauritius was mentioned in the report as an exception. According to the findings of the survey the country has a good e-strategy in place to become a "cyber island". The study also concluded that in those countries where projects such as e-learning, ehealth and e-commerce are started it is mostly done without a policy framework. As a direct outcome of these findings NEPAD adopted a recommendation of a broad and comprehensive continental ICT survey. Such a survey will help to identify current technical and regulatory obstacles that can jeopardise the development of a coherent ICT plan and infrastructure in Africa. An envisioned outcome of this initiative will be the development of a comprehensive database on ICT in Africa that will form the backbone of a ICT master plan for Africa (Baradu, 2005). It is not known to what extend this plan was put into practice by NEPAD.

There is however a political will in Africa to address these challenges. As a commitment to NEPAD's broadband infrastructure network project, Communication Ministers, representing various African countries, will sign a policy and regulatory framework protocol for a number of ICT infrastructure development projects, including the Eastern Africa Sub-marine System (EASSy) cable. This cable system will integrate intercontinental communication by connecting ICT infrastructure initiatives across Africa. This will enhance Africa's broadband connectivity largely (Fin24.com, 2006).

Another positive trend that will support access to OA journals is the exponential growth of ICT, both in terms of implementation and applications, on the African continent. This exponential growth is mainly due to huge financial support from amongst other the World Bank, the G8 countries as well as the United Nations. Up to 1995 only six countries in Africa were connected to the Internet. In the year 2002 nearly all the countries on the continent were connected in some or another way to the Internet (Ya'u, 2002:8).

\section{Telecommunication costs}

Although OA does not charge the end user, there are still production and communication costs involved. Accessing OA journals presupposes the availability of an Internet connection. The problem is that the cost of telecommunications in Africa is the most expensive in the world. This is mainly due to the lack of affordable and regular access to the Internet and insufficient policies regulating the telecommunications sectors. Broadband access tends to be unavailable, and when available, is a luxury that cannot be afforded by most people. In support of this argument, I quote part of a report released by ResearchICTAfrica.net on the Internet costs in Africa:

"In most countries in Europe and in the U.S.A., the prices of high speed Internet connections have declined dramatically in the last few years. Where ASDL technology is available, the cost per month for a $512 \mathrm{kbps}$. line is 25 to 40 USD per month. Dial-up lines cost about the same, if you include telephone charges for 15-25 
hours per month. In Africa, the cost of a dial-up connection is similar or often more expensive than in Europe, but only gives half the performance. A shared fixed line - often called a VPN (Virtual Private Network) - will often cost 300 to 500 USD, for a very mediocre performance. If you also consider the vast difference in incomes between most African countries and Europe, the difference becomes even greater. Measured as the number of hours you must work to pay for an Internet connection, a user in Africa is disadvantaged by a factor of 100 or more" (ResearchICTAfrica.net, 2005).

South Africa serves as a very good example of the high cost of telecommunications. Telkom has been the sole, fixed-line telecommunications operator in South Africa since 1991. In 2006 Telkom serves only around 2.4 million residential customers - out of a population of more than 43 million and their corporate customers include "more than 200 of the country's largest financial, retail, manufacturing and mining companies with domestic and international operations and approximately 550,000 large, medium and small businesses" (Telkom, 2006:4). Telkom has used this monopoly to its advantage - since the year 2000, its operating profit margin increased from RI.54 billion to just over R9 billion in the fiscal year ending in 2007. It is therefore no surprise that the telecommunications' costs in South Africa is currently one of the highest in the world, and studies have found that Telkom's pricing is excessive (Efficient Research, 2004; Genesis Analytics, 2004).

There are however some exiting developments in South Africa that will hopefully reduce the cost of telecommunication. A second fixed line telecom operator has been introduced in August 2006 which will hopefully bring the necessary competition to lower fixed line communication costs in South Africa. VOIP was also deregulated in 2005, opening up the possibility for cheaper calls and cheaper broadband access to the Internet. Vodacom and MTN, two mobile operators in South Africa, have also introduced a "third generation" mobile technology that can deliver broadband access to laptops. These new developments will hopefully allow more South Africans to communicate and be part of a global dialogue. The concern however remains: will it be affordable? According to Storm, a telecom firm operating in South Africa, some telecommunication costs in South Africa was in 2006 still on average 30 times more expensive that in the liberalised markets - in particular the USA and EU (Economist, September 2006:56). Even in 2009 telecommunication costs in South Africa are very high in comparison to the developed world.

This has had a severe effect on the financial ability of many scholars and universities to access OA journals online.

Lack of knowledge

One of the problems facing the OA movement is the fact that many researchers and scholars are not fully aware of the existence of $O A$ journals, and in cases where they are, couple this awareness with mistrust. There is a perception that $O A$ journals are not of the same academic value as 'traditional' journals. This has a two way effect: scholars are reluctant to publish in these journals and are also reluctant to use these journals as part of their research. Currently, there is a worldwide initiative to change this perception of OA journals.

\section{Conclusion}

In this paper, I have argued that OA journals provide an ideal opportunity for African scholars to gain access to the global body of scholarly research. OA journals offer a much better economic alternative than the current pricing structure of traditional publishers, and allow access online to anyone that has access to the Internet wherever they are in Africa.

As cited, there are, however, certain barriers to OA journals, and OA can certainly not be equated to universal access. The conclusion drawn from this is that African scholars are still in many ways marginalized when it comes to the access and use of OA scholarly materials.

\section{References}

African Economic Outlook. 2006. OECD Publication. Paris: African Development Bank.

Becker, K. 2003. Why intellectual property issues matter? World Information, special IP edition, (10-12 December 2003): I

Britz, J.J. 2006. A critical analysis of information poverty from a social justice perspective. PhD Dissertation: University of Pretoria: Pretoria.

Castells, M. 1998. End of millennium. In: The information age: economy, society and culture, vol. III. Malden: Blackwell.

Evans, P. B. \& Wurster, T. S. 1997. Strategies and the new economics of information. Harvard Business Review, (September): 7I82.

Economist. 2006. Better late than never: telecoms in South Africa. The Economist, September 2006: 56-57.

Efficient Research. 2004. An international comparison of South African telecommunication costs and the possible effect of telecommunications on economic performance and a report on Telkom's financial statements and comparisons with selected local and international companies [online]. Available: http://www.hellkom.co.za/media/EfficientResearch_TelkomReport.pdf (accessed November 13, 2006).

Genesis Analytics. (2004). Telecommunications prices in South Africa: an international peer group comparison [online]. Available: http://www.hellkom.co.za/media/Genesis_Telkom_Report.pdf (accessed November 17, 2006).

Inkanyiso, Jnl Hum \& Soc Sci 2009, I(I) 
Habermas, J. 1989. The structural transformation of the public sphere, translated by T. Burger. Cambridge, MA: MIT Press.

Hamelink, C. J. 2003. Moral challenges in the information society. Media Development, XLX(4): 40-43.

Kularatne, E. D. T. 1997. Information needs and information provision in developing countries. Information for Development, I3(3): I|7-12|.

Naisbitt, J. 1984. Megatrends: ten new directions transforming our lives. New York: Warner books

ResearchICTAfrica.net. 2005. Why is the Internet expensive in Africa? [Online].Available from: http://www.researchictafrica.net/ modules.php?op $=$ modload $\&$ name $=$ News $\&$ file $=$ article $\&$ sid $=30 \mathrm{I}$.

Sen, A. 1993. Capability and well-being. In: The quality of life, edited by M. Nussbaum and A. Sen. Oxford: Clarendon Press.

Suber, P. 2007. Open Access Overview. Available from: http://www.earlham.edu/ peters/fos/overview.htm

Telkom. (2006). Telkom Corporate Profile [online]. November 2006. Available from: http://www.telkom.co.za/pls/portal/docs/page/ contents/common/aboutus/Telkomprofile23_0I_07.pdf

United Nations Development Programme, 1999. Poverty report. New York: United Nations Publications.

Webster, F. 2002. Theories of the information society, second edition. London: Routledge

Ya'u, Y. Z. 2002. Confronting the digital divide: an interrogation of the African initiatives at bridging the gap. [Online]. Available from: http://www.codesria.org/Links/conferences/Nepad/yau.pdf. Accessed 17 October 2005 